\title{
Article \\ Characterization of a Recombinant Laccase B from Trametes hirsuta MX2 and Its Application for Decolorization of Dyes
}

\author{
Yitong Jia ${ }^{1}$, Qianqian Huang ${ }^{1}$, Lanlan Zhu ${ }^{2, *}$ and Chengyuan Pan ${ }^{1, *}$ (]) \\ 1 The Key Laboratory for Quality Improvement of Agricultural Products of Zhejiang Province, College of \\ Advanced Agricultural Sciences, Zhejiang A\&F University, Hangzhou 311300, China; \\ 2019601061002@stu.zafu.edu.cn (Y.J.); 2017701502006@stu.zafu.edu.cn (Q.H.) \\ 2 Science and Technology Service Center of Lin'an, Hangzhou 311300, China \\ * Correspondence: zhull@zju.edu.cn (L.Z.); cypan@zafu.edu.cn (C.P.)
}

check for updates

Citation: Jia, Y.; Huang, Q.; Zhu, L.; Pan, C. Characterization of a Recombinant Laccase B from Trametes hirsuta MX2 and Its Application for Decolorization of Dyes. Molecules 2022, 27, 1581. https://doi.org/ $10.3390 /$ molecules 27051581

Academic Editor: M. Amparo F. Faustino

Received: 28 January 2022

Accepted: 25 February 2022

Published: 27 February 2022

Publisher's Note: MDPI stays neutral with regard to jurisdictional claims in published maps and institutional affiliations.

Copyright: (C) 2022 by the authors. Licensee MDPI, Basel, Switzerland. This article is an open access article distributed under the terms and conditions of the Creative Commons Attribution (CC BY) license (https:// creativecommons.org/licenses/by/ $4.0 /)$.

\begin{abstract}
Trametes hirsuta is able to secrete laccase isoenzymes including constitutive and inducible forms, and has potential application for bioremediation of environmental pollutants. Here, an inducible group B laccase from T. hirsuta MX2 was heterologously expressed in Pichia pastoris, and its yield reached $2.59 \mathrm{U} / \mathrm{mL}$ after 5 days of methanol inducing culture. The optimal $\mathrm{pH}$ and temperature of recombinant laccase (rLac1) to 2,2'-azino-bis-(3-ethylbenzothiazoline-6-sulfonic acid) (ABTS) were 2.5 and $60{ }^{\circ} \mathrm{C}$, respectively. Metal ions showed different effect on $\mathrm{rLac} 1$ which $\mathrm{Mg}^{2+}, \mathrm{Cu}^{2+}$, and $\mathrm{K}^{+}$ increased enzyme activity as their concentration increased, whereas $\mathrm{Zn}^{2+}, \mathrm{Na}^{+}$, and $\mathrm{Fe}^{2+}$ inhibited enzyme activity as their concentration increased. rLac1 showed good tolerance to organic solvents, and more than $42 \%$ of its initial activity remained in $10 \%$ organic solvents. Additionally, rLac1 exhibited a more efficient decolorization ability for remazol brilliant blue R (RBBR) than for acid red 1 (AR1), crystal violet (CV), and neutral red (NR). Molecular docking results showed RBBR has a stronger binding affinity with laccase than other dyes by interacting with substrate binding cavity of enzyme. The results indicated rLac1 may be a potential candidate for dye removal from textile wastewater.
\end{abstract}

Keywords: laccase; Trametes hirsuta; dye; decolorization; characterization; heterologous expression

\section{Introduction}

Synthetic dyes including anthraquinone, azo, heterocycle, and triphenylmethane are widely used in textile, tannery and printing, cosmetic, paper, and pharmaceutical industries [1] It is estimated that more than 100,000 synthetic dyes are available globally, with annual production of over 1 million tons [2]. However, a large amount of dyes is released into wastewater in their industrial applications. For instance, about $20-50 \%$ of dyes are discharged into effluent during textile processing [3]. The recalcitrant chemical structure of some dyes and their intense coloration in water pose a serious threat to aquatic organisms $[4,5]$. The removal of dyes by adsorption, coagulation, ozonation, and chemical degradation is often high-cost and can generate hazardous by-products [6]. Biodegradation of synthetic dyes by enzymes has attracted increasing attention in recent years because its advantage of high efficiency and eco-friendly procedures in the treatment of dye effluent [7-9].

Laccase is a group of copper-containing oxidases that can catalyze the oxidation of phenolic and non-phenolic compounds, and is widely distributed in plants, fungi, bacteria, and insects [10]. In laccase-mediated catalytic reaction, water is the sole by-product produced by the transfer of electrons from hydrogen donating substrate to molecular oxygen. The extensive substrates and unique catalytic mechanism of laccase make it application in agricultural, industrial, medicinal, and environmental areas [11]. In recent years, more and more laccases have been proved to be the enzymes with great potential in the degradation of synthetic dyes $[9,12,13]$. The azonaphthol Orange 2 can be degraded by laccase from Trametes versicolor, with $72.8 \%$ decolorization [12]. Sun et al. observed that 
Gymnopusluxurians laccase exhibited efficient decolorization capability for 11 synthetic dyes with the help of the mediator of acetosyringone or syringaldehyde [14]. Among laccases derived from different organisms, fungal laccase has been considered as an ideal source of dye decolorization due to its high-redox potential [15].

Trametes hirsuta is a basidiomycete fungus that can secrete a variety of laccase isoenzymes $[8,16,17]$. Laccases obtained from different strains of $T$. hirsuta showed dissimilar decolorization ability to various types of dyes. For example, the crude laccase from $T$. hirsuta BT 2566 could decolorize more than $50 \%$ of the six azo dyes [18], and the laccase of T. hirsuta $\mathrm{Bm}-2$ displayed $97 \%$ decolorization to indigo carmine using natural mediators of phenol extracts [19]. RBBR and indigosol dye could be successfully degraded by laccase from T. hirsuta EDN 082 immobilized on light expanded clay aggregate [20,21]. It was further discovered that the laccase isoenzymes are encoded by multigene families, which contain seven functional genes and one non-processed pseudogene in T. hirsuta 072 [22]. However, not all laccase genes are constitutively expressed in the fungal transcriptomes and most of them need to be induced to expression by phenolic substances [22]. Savinova et al. classified the laccase isoenzymes from the fungi of the Polyporales order into A-H according to the homology of their encoding genes [23]. Group A laccases, as the constitutive isoenzymes (major laccases), are always secreted in the fungal secretomes regardless of culture conditions and have been sufficiently studied [24-26]. Group B-H laccases are the inducible isoenzymes (minor laccases) whose gene transcription is mosaic depending on both cultivation stages and growth conditions $[22,23]$. To the best of our knowledge, only two group $B$ laccases have been isolated and characterized from the original fungi. One was induced from Trametesvillosa by 2,5-xylidine, and its optimal $\mathrm{pH}$ was between 5 and 5.5 with syringaldazine as a substrate [27]. Another one was produced from T. hirsuta by growing in wood-based medium, and had an optimal pH of 2.5 to ABTS [8]. The limited data do not allow us to make definite inferences about group $B$ laccase properties.

Heterologous expression is an effective method to produce inducible laccase isoenzymeswhich are expressed at low levels or not at all in the original fungi. Three of the six minor laccases of T. hirsuta 072 were successfully obtained by expressing them in Penicillium canescens [28]. In addition, heterologous expression may also improve recombinant enzyme yields and may allow the production of laccases with desirable characteristics. A yield of Moniliophthoraroreri laccase up to $1.05 \mathrm{~g} / \mathrm{L}$ was detected when it was expressed in Pichia pastoris [29]. Compared to the native laccases, the recombinant laccases expressed heterologous host of $P$. pastoris showed more excellent properties including thermal stability, salt tolerance, specific activity, and alkaline resistance [30,31].

Previously, a laccase (Lac1) was purified and characterized from T. hirsuta MX2, and was identified as an inducible group B laccase by comparing its encoding gene with other fungal laccase gene sequences. Lac1 efficiently decolorizes synthetic dyes in the present of ABTS, but its yield from the original strain is relatively low to meet the industrial demand [8]. In this study, in order to increase the yield of Lac1, it was heterologously expressed in P. pastoris. The characteristics and dyes decolorization capability of recombinant Lac1 (rLac1) were investigated. The mechanism of dye decolorization by rLac1 was also elaborated employing molecular docking.

\section{Results}

\subsection{Screening and Expression of Laccase Recombinants}

A 1500 bp nucleotide sequence of $L a c 1$ without native signal peptide was amplified from T. hirsuta MX2 by using specific primers. The Lac1 was ligated into pPIC9K to generate expression vector PPIC9K-Lac1, which was then integrated into the P. pastoris genome by electroporation. In MD screening medium, forty yeast recombinants were randomly selected for detection of laccase activity in a 96-well plate (Figure 1a). The positive recombinants with laccase activity were verified by adding ABTS into BMMY for color reaction, and a colony showing dark green (numbered of 10) was used for subsequent recombinant laccase production (Figure 1b). The colony was inoculated into 1 L BMMY 
medium and cultured under methanol induction. Laccase activity was detected in the culture liquid, and reached the highest value of $2.59 \mathrm{U} / \mathrm{mL}$ after 5 days of culture (Figure 1c).

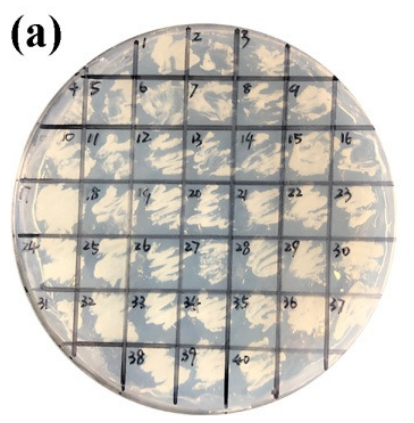

(b)

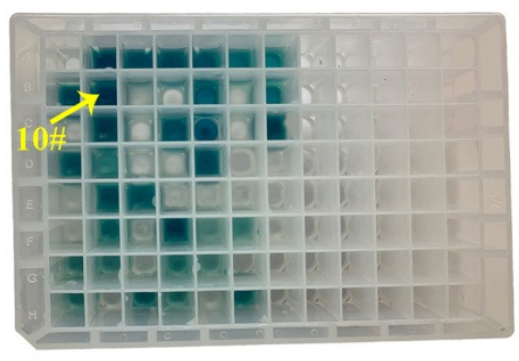

(c)

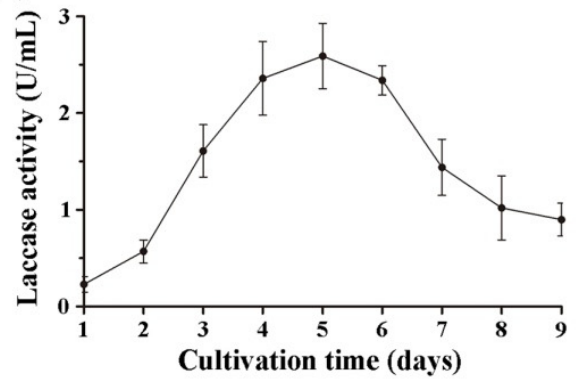

Figure 1. Screening of P. pastoris recombinants and laccase activity. (a) Growing of recombinants on a histidine-deficient MD agar plate. (b) Screening of recombinants with laccase activity in BMMY medium containing ABTS. (c) The activity of recombinant laccase in BMMY liquid medium. The values were mean $\pm \mathrm{SD}$.

\subsection{Purification of Recombinant Laccase}

Supernatant of the colony 10 cultured for 5 days in BMMY was used to purify rLac1. Purification steps included ultrafiltration, ammonium sulfate precipitation, and anion exchange chromatography. Laccase activity and protein concentration were determined for each purified product. Total activity was reduced from $2235 \mathrm{U}$ in the culture supernatant to $129 \mathrm{U}$ after purification, however specific activity was correspondingly increased from 19.1 to $92.1 \mathrm{U} / \mathrm{mg}$ (Table 1). It can be seen from the zymogram result in Figure 2a that there was only one band of rLac1 in both the culture supernatant and purified fraction. The deeper green band in the purified fraction than in the culture supernatant also indicated that rLac1 had been enriched after purification (Figure 2a). SDS-PAGE analysis showed that the molecular weight of rLac1 was about $63 \mathrm{kDa}$ (Figure 2b).

(a)

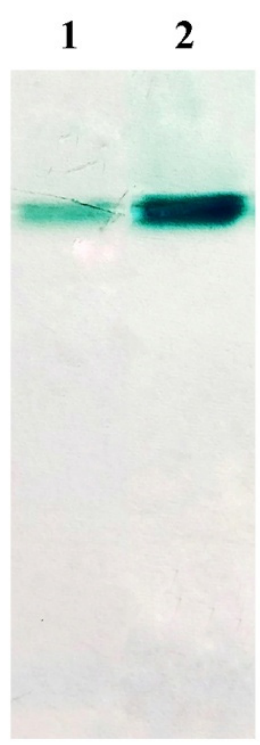

(b)

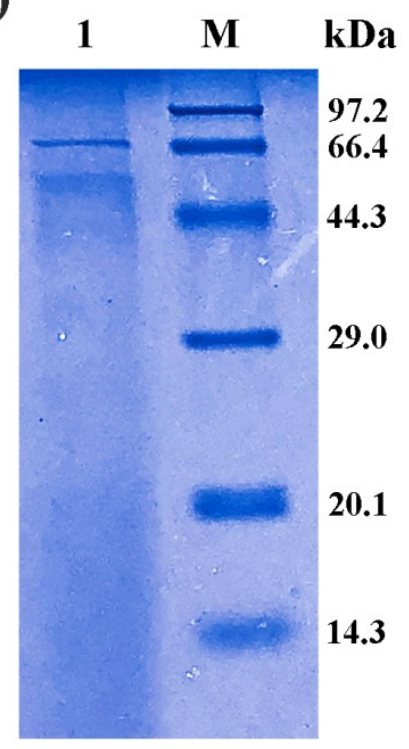

Figure 2. Electrophoresis of purified rLac1. (a) Zymogram analysis of rLac1 using ABTS as substrate, line 1 is rLac1 in the culture supernatant, and line 2 is purified rLac1. (b) Molecular weight analysis of rLac1 by SDS-PAGE, line 1 is purified $\mathrm{rLac1}$, and line $\mathrm{M}$ is the protein marker. 
Table 1. Purification of rLac1 from T. hirsuta MX2.

\begin{tabular}{ccccccc}
\hline Purification Step & $\begin{array}{c}\text { Total Volume } \\
(\mathbf{m L})\end{array}$ & $\begin{array}{c}\text { Total Activity } \\
\text { (U) }\end{array}$ & $\begin{array}{c}\text { Total Protein } \\
\text { (mg) }\end{array}$ & $\begin{array}{c}\text { Specific Activity } \\
\text { (U/mg) }\end{array}$ & $\begin{array}{c}\text { Percent } \\
\text { Recovery (\%) }\end{array}$ & $\begin{array}{c}\text { Purification } \\
\text { Fold }\end{array}$ \\
\hline Culture supernatant & 870 & 2235 & 116.8 & 19.1 & 100 & 1 \\
Ultrafiltrate & 186 & 1971 & 53.6 & 36.8 & 88.2 & 1.9 \\
$\left(\mathrm{NH}_{4}\right)_{2} \mathrm{SO}_{4}$ precipitation & 30 & 484 & 7.8 & 62.1 & 21.7 & 3.3 \\
$\mathrm{DEAE}-S e p h a r o s e \mathrm{FF}$ & 14 & 129 & 1.4 & 92.1 & 5.8 & 4.8 \\
\hline
\end{tabular}

\subsection{Characterization of Recombinant Laccase}

The purified rLac1 showed maximal oxidation activity to ABTS at pH 2.5 (Figure 3a). The activity declined slowly at $\mathrm{pH} 2.5-4.0$, but decreased rapidly at $\mathrm{pH}$ above 4.0 . rLac1 completely inactivated at $\mathrm{pH} \geq 6.0$. $\mathrm{pH}$ stability gradually increased when increasing reaction $\mathrm{pH}$ above 2.5. The residue activity of $\mathrm{rLac} 1$ remained between $65.6-86.2 \%$ after incubation at $\mathrm{pH} 2.0-5.5$ for $72 \mathrm{~h}$. rLac1displayed maximal activity at $60^{\circ} \mathrm{C}$, and the activity decreased rapidly when temperature was increased to $80^{\circ} \mathrm{C}$ and higher (Figure $3 \mathrm{~b}$ ). Poor thermostability was observed from the results in Figure $3 \mathrm{~b}$ when rLac1 was inoculated at temperature above $50{ }^{\circ} \mathrm{C}$. The residue activity was close to zero after incubated at $60{ }^{\circ} \mathrm{C}$ for $30 \mathrm{~min}$.
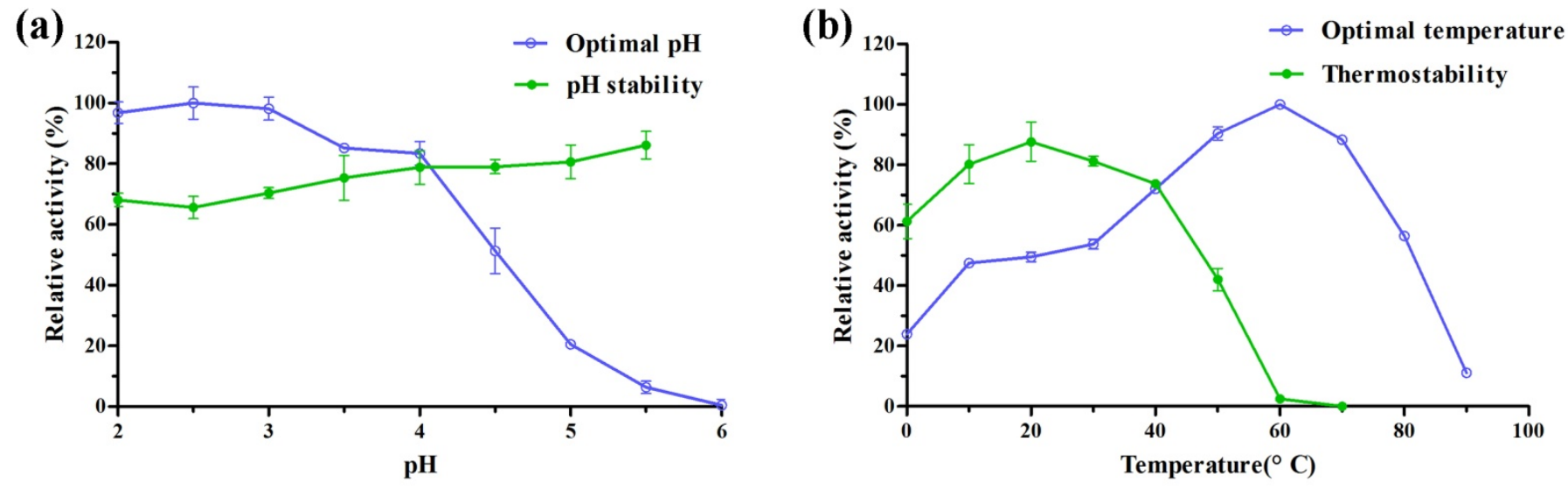

Figure 3. Effects of $\mathrm{pH}$ and temperature on the activity and stability of rLac1. (a) Optimal pH and stability of rLac1, the $\mathrm{pH}$ stability was showed as the percentage of residual activity after incubation at different $\mathrm{pH}$ values for $72 \mathrm{~h}$. (b) Optimal temperature and stability of rLac1, the thermostability was showed as the percentage of residual activity after incubation at different temperatures for $30 \mathrm{~min}$. The values were mean $\pm S D$.

$K_{\mathrm{m}}$ and $k_{\text {cat }}$ values of rLac1 were determined using ABTS and DMP as substrates. The results in Table 2 showed that ABTS was more easily bound by rLac1 than DMP with the $K_{\mathrm{m}}$ value of $28.4 \mu \mathrm{M}$ for ABTS and $K_{\mathrm{m}}$ of $394.1 \mu \mathrm{M}$ for DMP. rLac1 exhibited a higher catalytic turnover rate for ABTS $\left(k_{\text {cat }}=343.2 \mathrm{~s}^{-1}\right)$ than DMP $\left(k_{\text {cat }}=141.7 \mathrm{~s}^{-1}\right)$.

Table 2. Kinetic constants of native (Lac1) and recombinant laccase (rLac1) from T. hirsuta MX2.

\begin{tabular}{|c|c|c|c|c|c|c|}
\hline \multirow{2}{*}{ Substrate } & \multicolumn{3}{|c|}{ Lac1 * } & \multicolumn{3}{|c|}{ rLac1 } \\
\hline & $K_{\mathrm{m}}(\mu \mathrm{M})$ & $k_{\mathrm{cat}}\left(\mathrm{s}^{-1}\right)$ & $k_{\text {cat }} / K_{\mathrm{m}}\left(\mathbf{M}^{-1} \mathrm{~s}^{-1}\right)$ & $K_{\mathrm{m}}(\mu \mathrm{M})$ & $k_{\text {cat }}\left(\mathrm{s}^{-1}\right)$ & $k_{\text {cat }} / K_{\mathrm{m}}\left(\mathrm{M}^{-1} \mathrm{~s}^{-1}\right)$ \\
\hline ABTS & 22.4 & 91.7 & $4.1 \times 10^{6}$ & 28.4 & 343.2 & $1.2 \times 10^{7}$ \\
\hline DMP & 351.7 & 28.4 & $8.1 \times 10^{4}$ & 394.1 & 141.7 & $3.6 \times 10^{5}$ \\
\hline
\end{tabular}

${ }^{*}$ Results were described by Huang et al. [8].

The effect of metal ions on rLac1 activity was dose-dependent (Figure 4). Metal ions such as $\mathrm{Mg}^{2+}, \mathrm{Cu}^{2+}$, and $\mathrm{K}^{+}$enhanced rLac1 activity with their concentration increased, 
especially $\mathrm{Cu}^{2+}$, which enhanced $68.9 \%$ of activity in the concentration of $100 \mathrm{mM}$. Conversely, the activities were inhibited by $\mathrm{Zn}^{2+}$ and $\mathrm{Na}^{+}$with their concentration increased. rLac1 activity was almost completely inhibited by $\mathrm{Fe}^{2+}$, and only $3.2 \%$ of residual activity was determined in present of $\mathrm{Fe}^{2+}$ at $1 \mathrm{mM}$ concentration.

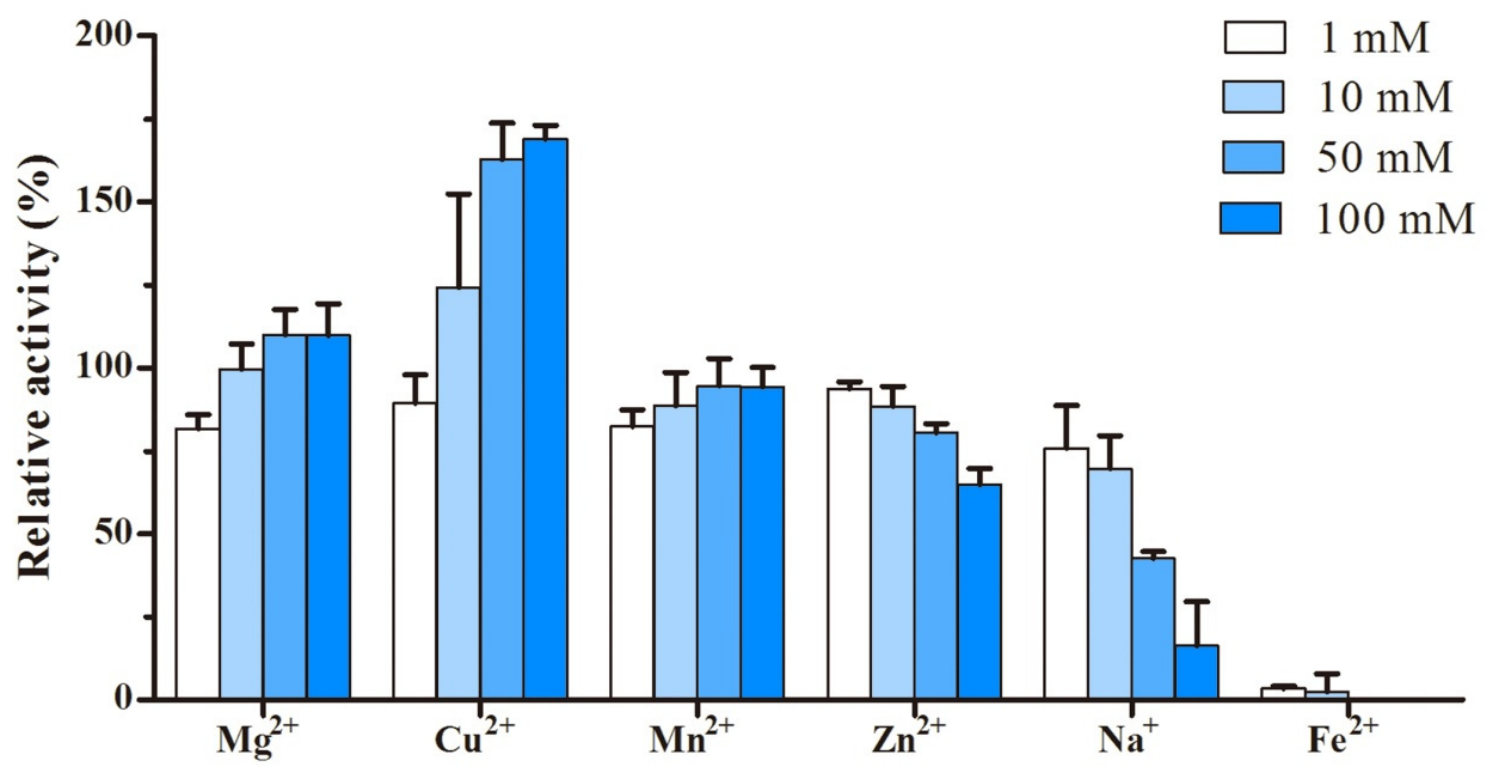

Figure 4. Effect of metal ions on the activity of rLac1. Activity was measured at $30{ }^{\circ} \mathrm{C}$ in citrate phosphate buffer (100 mM, pH 5.0). The values were mean \pm SD.

The effects of organic solvents of acetone, acetonitrile, dimethylsulfoxide, ethanol, methanol, and isopropanol on rLac1 activity were investigated. rLac1 displayed some certain degrees of tolerance to six organic solvents. In presence of $5 \%$ and $10 \%$ organic solvents, the relative activities of rLac1 were more than $64 \%$ and $42 \%$, respectively (Table 3 ). rLac1 was significantly inhibited by organic solvents at a concentration of $50 \%$.

Table 3. Effect of organic solvents on the activity of rLac1.

\begin{tabular}{cccc}
\hline \multirow{2}{*}{ Organic Solvents $(v / v)$} & \multicolumn{3}{c}{ Relative Activity } \\
\cline { 2 - 4 } & $\mathbf{5 \%}$ & $\mathbf{1 0} \%$ & $\mathbf{5 0 \%}$ \\
\hline Acetone & $69.1 \pm 7.8$ & $44.2 \pm 3.9$ & $0.4 \pm 0.6$ \\
Acetonitrile & $80.0 \pm 12.3$ & $61.3 \pm 3.1$ & $9.0 \pm 0.2$ \\
Dimethylsulfoxide & $64.5 \pm 6.4$ & $43.9 \pm 1.4$ & $4.3 \pm 2.3$ \\
Ethanol & $70.0 \pm 4.3$ & $53.3 \pm 2.8$ & $7.0 \pm 1.0$ \\
Methanol & $86.2 \pm 7.3$ & $62.4 \pm 3.1$ & $3.0 \pm 0.9$ \\
Isopropanol & $65.2 \pm 9.8$ & $42.5 \pm 8.8$ & \\
\hline
\end{tabular}

\subsection{Dye Decolorization}

The decolorization capability of rLac1 on anthraquinone (RBBR), azo (AR1), triphenylmethane $(\mathrm{CV})$, and heterocycle (NR) was investigated. rLac1 exhibited a strong decolorization ability for RBBR with $92.57 \%$ of decolorization rate after $3 \mathrm{~h}$ reaction in the absence of ABTS, whereas the decolorization to AR1, CV, and NR was weaker and decolorization rates were $15.3 \%, 14.2 \%$, and $12.3 \%$, respectively (Table 4 ). When ABTS was added to the reaction, the decolorization rates of $\mathrm{rLac} 1$ to $\mathrm{RBBR}, \mathrm{AR} 1, \mathrm{CV}$, and NR were increased to $99.2 \%, 67.1 \%, 38.9 \%$, and $52.3 \%$, respectively. 
Table 4. Dye decolorization of the recombinant (rLac1) T. hirsuta MX2 laccase.

\begin{tabular}{|c|c|c|}
\hline Dyes & Mediator & Decolorization Rate (\%) \\
\hline \multirow{2}{*}{ RBBR } & - & $92.6 \pm 0.9$ \\
\hline & + & $99.2 \pm 0.6$ \\
\hline \multirow{2}{*}{ AR 1} & - & $15.3 \pm 0.8$ \\
\hline & + & $67.1 \pm 0.4$ \\
\hline \multirow{2}{*}{$\mathrm{CV}$} & - & $14.2 \pm 0.4$ \\
\hline & + & $38.9 \pm 0.9$ \\
\hline \multirow{2}{*}{ NR } & - & $12.3 \pm 0.3$ \\
\hline & + & $52.3 \pm 0.5$ \\
\hline
\end{tabular}

- Decolorization by laccase in the absence of ABTS mediator. + Decolorization by laccase in the presence of ABTS mediator.

\subsection{Molecular Docking}

Here, molecular docking was used to explore the interaction mechanism between laccase protein and dye molecules. All four dyes can bind to the SBC which located in the $\mathrm{Cu}$ T1 site of laccase (Figure 5). RBBR interacts with amino acid residues N208, Q237, N264, G392, and A393 on laccase via H-bond. N264, G392, and A393 were found as active site residues for laccase to interact with AR1. NR was observed to interact with laccase through P163, while no amino acid residue involved in the binding mechanism between $\mathrm{CV}$ and laccase. The binding energies of laccase with RBBR, AR1, CV, and NR were $-6.8 \mathrm{kcal} / \mathrm{mol}$, $-6.4 \mathrm{kcal} / \mathrm{mol},-6.5 \mathrm{kcal} / \mathrm{mol}$, and $-5.1 \mathrm{kcal} / \mathrm{mol}$, respectively.
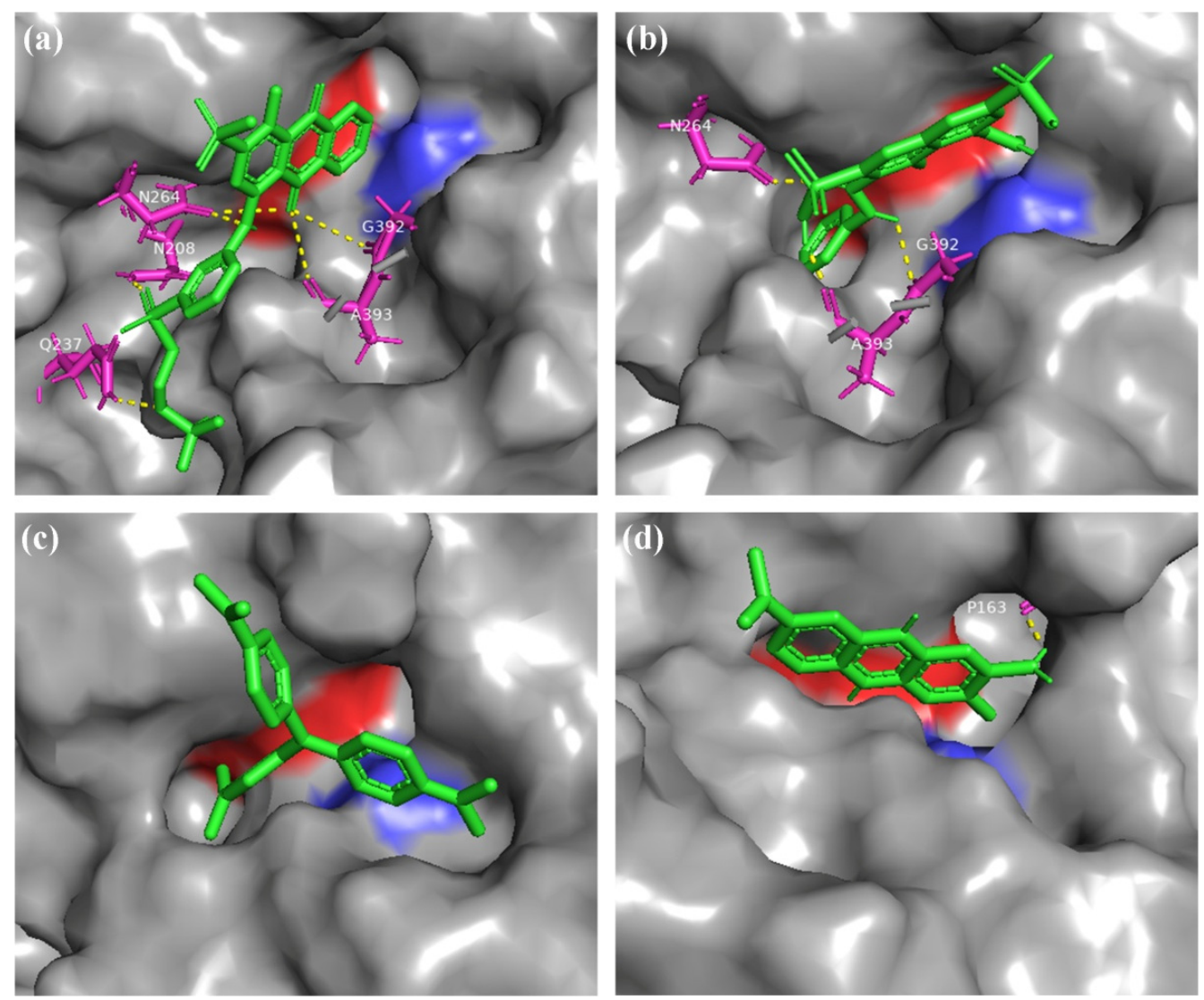

Figure 5. Molecular docking results of laccase with dye molecules of RBBR (a), AR1 (b), CV (c), or NR (d). The green and pink models represent dye molecules and their docking amino acids, respectively. The yellow dashes indicate $\mathrm{H}$-bonds. The blue and red shadows represent conserved histidine $\left(\mathrm{H}_{458}\right)$ and acidic aspartic acid $\left(\mathrm{D}_{206}\right)$ in the substrate binding cavity of laccase, respectively. 


\section{Discussions}

Fungal laccases are promising enzymes for decolorization and detoxification of dyes, but the low production levels in original fungi limit their industrial applications. The expression of laccases in heterologous hosts, such as bacteria, filamentous fungi, and yeast is an effective method to increase their production [32]. Among those hosts, P. pastoris has received more attention because of its easy to manipulation and high protein secretion capacity $[29,33,34]$, and has successfully expressed so far over 40 fungal laccases [35]. $T$. hirsuta is one of the fungi that intensively used to produce laccase. Two types of laccase, constitutive and inducible forms, can be secreted from the fungus [17]. LacA, as a constitutive laccase, has been expressed in filamentous fungus of Aspergillus nidulans, and the highest laccase activity of $2.0 \mathrm{U} / \mathrm{mL}$ was observed in the culture liquid [36]. Three inducible laccases of $\mathrm{LacC}, \mathrm{LacD}$, and $\mathrm{LacF}$ have been also expressed in P. canescens, and the activities of recombinant laccases were more than $100 \mathrm{U} / \mathrm{mL}$ in the culture broth [26]. In this study, Lac1, as an inducible laccase of group B from T. hirsuta MX2 [8], was firstly expressed in P. pastoris. A yeast recombinant with high laccase activity was screened, and its activity was five times higher than that of the original strain [8].

The purified recombinant laccase of rLac1 was used to compare with other group B laccases of Trametes in properties. As showed in Figure 2, rLac1 exhibited a slightly higher molecular weight than native Lac1 of $61.4 \mathrm{kDa}$ reported previously [8]. Higher molecular weight of heterologous-expressed laccases has also been observed in other reports $[30,35]$, which may be associated with higher glycosylation levels of recombinant laccases.

Generally, inducible laccases such as groups B-H are characterized with neutral optimal $\mathrm{pH}$ [27]. Koschorreck et al. found that the optimal $\mathrm{pH}$ of a recombinant group $\mathrm{B}$ laccase from T. versicolor was determined in 1.9 [37]. Similarly, optimal pH of rLac1 in acidic regions was displayed in this study. Although the optimal temperature of group B laccase could reach to $75^{\circ} \mathrm{C}$, it is generally not stable at high temperatures [27,37]. Previous study found that native Lac1 of T. hirsuta MX2 has a half-life of $0.88 \mathrm{~h}$ at $60^{\circ} \mathrm{C}$ [8]. Here, rLac1 showed a lower thermostability than Lac1, and was almost inactive after incubated at $60^{\circ} \mathrm{C}$ for $30 \mathrm{~min}$ (Figure 3).

ABTS is generally more suitable for use as a substrate for fungal laccase than DMP. This study also found that the affinity and catalytic efficiency of rLac1 to ABTS were better than that to DMP (Table 2). Compared with native Lac1, the $k_{\text {cat }}$ values of rLac1 to ABTS and DMP were increased, which could be found in the study of Xu et al. [31].

Metal ions and organic solvents often occur in textile dye wastewater. If laccase is used to remove dyes from wastewater, it is necessary to evaluate the effect of these factors on laccase activity. In this study, rLac1 showed a strong tolerance to metal ions of $\mathrm{Mg}^{2+}, \mathrm{Mn}^{2+}$, and $\mathrm{Zn}^{2+}$, and its activity was still retained over $60 \%$ in the presence of these ions at $100 \mathrm{mM}$, while $\mathrm{Fe}^{2+}$ inhibited enzyme activity (Figure 4). $\mathrm{Cu}^{2+}$ is considered to be an inducer of laccase activity, but the activity promotion often occurs at low concentrations $[34,38,39]$. However, the activity of rLac1 was obviously improved by $\mathrm{Cu}^{2+}$ at high concentration $(100 \mathrm{mM})$. In addition, Vasina et al. reported that $l a c B$, encoding gene of group B laccase, was also expressed at a higher level induced by copper than other groups of laccase genes [40]. Therefore, it may be believed that $\mathrm{Cu}^{2+}$ is helpful to the improvement of the activity of group B laccase and its production in Trametes. Fungal laccase is usually highly sensitive to $\mathrm{Fe}^{2+}$, probably due to the competitive inhibition of $\mathrm{Fe}^{2+}$ in laccase electron transport $[34,39,41]$. The concentration of organic solvent seems to be a critical factor affecting laccase activity. At low concentration, organic solvents have little effect on laccase activity, and even promote it. For example, laccase activities from Lentinula edodes and Kurthiahuakuii were enhanced in the presence of $10-15 \%$ of methanol and ethanol [42,43]. However, most fungal laccases will become inactive in organic solvents above $10 \%$ [29,44]. Although no enhancement in rLac1 activity by solvents was observed in this study, rLac1 could tolerate organic solvents to some extent, and retained over $42 \%$ of the original activity in $10 \%$ organic solvents. The loss of laccase activity in the present of organic solvents may 
be caused by the unfolding of laccase protein or the competing binding of organic solvent to the active center of laccase [42,44].

T. hirsuta is considered to be a promising fungus in dye decolorization by employing its own secreted laccase isoenzymes. These isoenzymes perform different functions during dye decolorization, and inducible laccases generally exhibit better decolorization ability than constitutive laccases [8,28]. rLac1, as an inducible laccase, was found to have excellent decolorization of RBBR, and its decolorization rate is more than $90 \%$ regardless of the presence or absence of ABTS (Table 4). In comparison, the decolorization rate of laccase from $T$. pubescens and Fusarium oxysporum to RBBR is much lower in the absence of mediator [34,41]. ABTS is the first synthetic mediator for laccase, and has been shown to enhance the decolorization ability of laccase. This enhancement may be resulted from the involvement of ABTS in electron transfer during laccase-induced dye decolorization [45]. Similarly, the decolorization rates of AR1, CV, and NR by rLac1 in the presence of ABTS are significantly higher than that without ABTS in this study, indicating that the decolorization of these dyes by rLac1 requires the participation of mediator. In addition, a comparative analysis of recombinant rLac1 and native Lac1 to dye decolorization was conducted. The results showed the decolorization rates of rLac1 to RBBR, AR1, and NR were higher than that of Lac1 (Table 4) [8]. Similar observations were found in the recombinant laccase of Coprinopsis cinerea, in which the decolorization ability of recombinant laccase was improved compared with that of native laccase [31]. Although the mechanism of improving decolorization ability of recombinant laccases is not clear so far, they tend to have different glycosylation patterns and levels than the native laccases $[35,46]$. The glycosylation of recombinant laccases not only affects their physicochemical properties, but also may help to improve the decolorization ability of laccases [30].

The active site of laccase occurs around four copper ions, where $\mathrm{T} 1 \mathrm{Cu}$ is the site of substrate binding and oxidation. Dyes interact with amino acid residues around $\mathrm{T} 1 \mathrm{Cu}$ mainly by hydrogen bonding, and binding to laccase protein [47]. In molecular docking test, the binding site between dye and laccase was set in T1 Cu SBC, in which contains a highly conserved histidine and acidic aspartic acid (Figure 5) [48]. The results showed that RBBR displayed more hydrogen bonds and higher binding energy with laccase than other tested dyes, which may account for the higher decolorization rate of laccase to RBBR.

\section{Materials and Methods}

\subsection{Strains, Vector, and Culture Media}

T. hirsuta MX2 was isolated from decayed wood with high laccase activity, and was used as the source strain of laccase gene in this study [8]. pMD 19-T vector (TaKaRa, Kusatsu, Japan) was used for gene cloning of PCR. P. pastoris GS115 strain and pPIC9K vector purchased from Invitrogen (Carlsbad, CA, USA), and were used for laccase heterologous expression. Liquid medium (LM) $(w / v)(2 \%$ poplar dust, $1 \%$ yeast extract, $0.2 \%$ $\left.\mathrm{KH}_{2} \mathrm{PO}_{4}, 0.2 \%\left(\mathrm{NH}_{4}\right)_{2} \mathrm{SO}_{4}, 0.05 \% \mathrm{MgSO}_{4} \cdot 7 \mathrm{H}_{2} \mathrm{O}, 0.01 \% \mathrm{CaCl}_{2}\right)$ was used to induce laccase production in T. hirsuta MX2 as our previously report [8]. Minimal dextrose medium (MD) $(w / v)$ ( $2 \%$ dextrose, $1.34 \%$ yeast nitrogen base, $4 \times 10^{-5} \%$ biotin) was selected to screen recombinants of P. pastoris. Buffered glycerol-complex medium (BMGY) $(w / v)(2 \%$ peptone, $1 \%$, yeast extract, $1.34 \%$ yeast nitrogen base, $0.1 \mathrm{M}$ potassium phosphate $(\mathrm{pH} 6.0), 0.5 \%$ glycerol, $4 \times 10^{-5} \%$ biotin) was used to culture strain of P. pastoris. Buffered methanolcomplex medium (BMMY) $(w / v)$ (as BMGY, methanol instead of glycerol) was conducted to induce the production of recombinant laccase.

\subsection{Cloning of Laccase Gene}

MX2 mycelium grown in LM for seven days was harvested. Total RNA was isolated using MiniBest RNA Extraction kit (TaKaRa, Japan), and PrimeScript II cDNA Synthesis kit (TaKaRa, Japan) was used for synthesizing first strand cDNA according to the manufacturer's instructions. 
Based on laccase nucleotide sequence (Lac1) from T. hirsuta MX2 (GenBank accession number: MN327569), two primers of Lac1-F (5'-CGGAATTCGCCATTGGACCGAAGGCGAACCTCG-3') and Lac1-R (5'-ATTTGCGGCCGCTCACAGATCGCCCTCCGCCAGCTTG$3^{\prime}$ ) were designed to amplify gene sequence encoding mature peptide of Lac1. Two restriction sites of EcoR I and Not I were introduced at the $5^{\prime}$ and $3^{\prime}$ ends of the PCR products, respectively. The PCR procedure was: initial denaturation at $98{ }^{\circ} \mathrm{C}$ for $10 \mathrm{~s} ; 33$ cycles of $98^{\circ} \mathrm{C}$ for $10 \mathrm{~s}, 65^{\circ} \mathrm{C}$ for $5 \mathrm{~s}$, and $72{ }^{\circ} \mathrm{C}$ for $1.5 \mathrm{~min}$; final extension at $72{ }^{\circ} \mathrm{C}$ for $10 \mathrm{~min}$. The PCR products were analyzed on $1.5 \%$ agarose gel. The band of approximately $1.5 \mathrm{~kb}$ in size was purified, ligated into pMD 19-T and verified by sequencing.

To expression in $P$. pastoris, the sequence of Lac1 was separated from recombinant pMD 19-T vector by EcoR I and Not I restriction enzymes, and was ligated into EcoR I-Not I-digested pPIC9K, designating pPIC9K-Lac1. The pPIC9K-Lac1 was then linearized with Sac I, and was transferred into P. pastoris GS115 by electroporation. Positive transformants were selected after 3 days in MD medium.

\subsection{Screening and Expression of Laccase Recombinants}

In order to screen transformations with laccase activity, forty P. pastoris colonies were randomly picked up from the MD medium, and re-inoculated into a new MD plate. After 4 days of culture at $28^{\circ} \mathrm{C}$, the colonies were successively inoculated into a 96-well plate containing $500 \mu \mathrm{L}$ BMMY medium, and were cultured at $28^{\circ} \mathrm{C}$ for $24 \mathrm{~h}(250 \mathrm{rpm})$. ABTS $(200 \mu \mathrm{L}, 1 \mathrm{mM}, \mathrm{pH} 4.0)$ was added to BMMY medium and the colonies with laccase activity were detected by observing appearance of green color after a period of reaction. The greenest colony was selected for scale-up (1 L culture scale) production of laccase. Briefly, the colony was grown in $25 \mathrm{~mL}$ BMGY medium for $24 \mathrm{~h}$ at $28^{\circ} \mathrm{C}(250 \mathrm{rpm})$. The cells were harvested by centrifugation at $4000 \mathrm{rpm}$ for $5 \mathrm{~min}$, resuspended in $1 \mathrm{~L}$ BMMY medium, and cultured at $28^{\circ} \mathrm{C}$ and $250 \mathrm{rpm}$. During the colony culture, $10 \mathrm{~mL}$ methanol was added to BMMY medium daily to induce laccase production, and $1 \mathrm{~mL}$ culture liquid was collected every day for laccase activity determination.

\subsection{Laccase Activity Assay}

Laccase activity was determined as described in our previous report [8] by monitoring the absorbance at $420 \mathrm{~nm}$ for the oxidation of ABTS $\left(\varepsilon_{420}=36,000 \mathrm{M}^{-1} \mathrm{~cm}^{-1}\right)$. For this, $0.5 \mathrm{~mL}$ of culture supernatant was mixed into $3 \mathrm{~mL}$ of $100 \mathrm{mM}$ citrate phosphate buffer (pH 5.0) containing $0.5 \mathrm{mM}$ ABTS and incubated at $25^{\circ} \mathrm{C}$. For purified rLac1, a $20 \mu \mathrm{L}$ amount of enzyme was added to the $300 \mu \mathrm{L}$ reaction mixture. One unit of laccase activity was defined as the amount of enzyme leading to the oxidation of $1 \mu$ mol of ABTS per min. Protein concentration was estimated using the Bradford method with bovine serum albumin as a standard.

\subsection{Purification of Recombinant Laccase}

Recombinant with high laccase activity was cultured in BMMY medium at $28{ }^{\circ} \mathrm{C}$ and shaken at $250 \mathrm{rpm}$. The culture supernatant was harvested at the day 5 by centrifugation (4000 rpm) at $4{ }^{\circ} \mathrm{C}$, and filtered with a Millipore tube (cutoff $10 \mathrm{kDa}$ proteins). The filtered supernatant was collected for $\left(\mathrm{NH}_{4}\right)_{2} \mathrm{SO}_{4}$ precipitation (80\% saturation), and the precipitated proteins were dialyzed with $20 \mathrm{mM}$ citrate phosphate buffer $\left(\mathrm{pH} \mathrm{5.0)}\right.$ at $4{ }^{\circ} \mathrm{C}$ for $12 \mathrm{~h}$. The dialyzed sample was added to a pre-equilibrated DEAE-Sepharose FF column and separated by anion exchange chromatography. Eluted liquid contained $0.5 \mathrm{M} \mathrm{NaCl}$ in $20 \mathrm{mM}$ citrate phosphate buffer ( $\mathrm{pH}$ 5.0). The fractions with laccase activity were collected and concentrated by ultrafiltration. Molecular weight of rLac1 was determined using SDS-PAGE. Zymogram analysis was conducted using native-PAGE stained with ABTS.

\subsection{Characterization of Recombinant Laccase}

The optimal $\mathrm{pH}$ of rLac1 was estimated by determining enzyme activity toward ABTS in $\mathrm{pH}$ values of 2.0 to 6.0 . The reactions were carried out at $30^{\circ} \mathrm{C}$ in citrate phosphate buffer 
(100 $\mathrm{mM})$. The $\mathrm{pH}$ stability was evaluated by calculating the residue activity after incubation rLac1 in buffer with $\mathrm{pH}$ values of 2.0 to 5.5 for $72 \mathrm{~h}$. The optimal temperature was examined by measuring the enzyme activity of rLac1 between 0 and $90^{\circ} \mathrm{C}$. The thermostability of rLac1 was determined by evaluating the residual activity for $30 \mathrm{~min}$ in buffer with various temperatures $\left(0-70{ }^{\circ} \mathrm{C}\right)$.

$K_{\mathrm{m}}$ and $k_{\text {cat }}$ values of rLac1 against ABTS and DMP were determined at pH 5.0 and $50{ }^{\circ} \mathrm{C}$ using the Lineweaver-Burk double-reciprocal plot [8]. Laccase activity toward 2,6dimethoxyphenol (DMP) was measured by recording the change of absorbance value at $469 \mathrm{~nm}\left(\varepsilon_{469}=27,500 \mathrm{M}^{-1} \mathrm{~cm}^{-1}\right)$.

The effect of metal ions $\left(\mathrm{Mg}^{2+}, \mathrm{Cu}^{2+}, \mathrm{Mn}^{2+}, \mathrm{Zn}^{2+}, \mathrm{Na}^{+}\right.$, and $\left.\mathrm{Fe}^{2+}\right)$ and organic solvents (acetone, acetonitrile, dimethylsulfoxide, ethanol, methanol, and isopropanol) on the activity of rLac1 were investigated by measuring the relative activity of the enzyme to ABTS. Considering the stability and practical application of $\mathrm{rLac1}$, the treatment conditions were set at pH 5.0 and $30^{\circ} \mathrm{C}$. The activity of rLac1 without any of the effectors was taken as $100 \%$.

\subsection{Dye Decolorization}

The decolorization abilities of rLac1 to RBBR, AR1, CV, and NR were determined as described in Huang et al. [8]. $0.05 \mathrm{U} / \mathrm{mL}$ of $\mathrm{rLac} 1$ was mixed with $150 \mathrm{mg} / \mathrm{L} \mathrm{RBBR}$ $\left(\lambda_{\max }=592 \mathrm{~nm}\right), 15 \mathrm{mg} / \mathrm{L}$ AR1 $\left(\lambda_{\max }=529 \mathrm{~nm}\right), 60 \mathrm{mg} / \mathrm{LCV}\left(\lambda_{\max }=590 \mathrm{~nm}\right)$, and $5 \mathrm{mg} / \mathrm{LNR}\left(\lambda_{\max }=530 \mathrm{~nm}\right)$ into $1 \mathrm{~mL}$ of reaction system, respectively. The decolorization reaction was performed at $28^{\circ} \mathrm{C}$ in the absence or presence of ABTS $(0.1 \mathrm{mM})$ in pH 5.0 buffer. The decolorization rate of each dye was calculated by measuring the decrease of the maximum absorbance of each dye after $3 \mathrm{~h}$ of reaction. The equation was as follows:

$$
\text { Decolorization rate }(\%)=[(\mathrm{Ai}-\mathrm{Af}) / \mathrm{Ai}] \times 100 \%
$$

here, $A_{i}$ and $A_{f}$ represented the initial and final absorbance of the reaction, respectively.

\subsection{Molecular Docking between Laccase and Dyes}

Molecular dockings between laccase and dye molecules were operated with the AutoDock tools [49]. The 3D structure of laccase (PDB: 1GYC) was retrieved from PDB (https: / / www.pdbus.org, accessed on 28 December 2021), and the original ligands and water molecules were removed from the laccase protein using PyMOL [50]. The 3D models of RBBR, AR1, CV, and NR were obtained from PubChem (https:/ / pubchem.ncbi.nlm.nih.gov, accessed on 26 December 2021). After adding hydrogen, fixing charge and torsion, laccase protein and dye molecules were used for docking process. The grid box was arranged around the protein's substrate binding cavity (SBC) [48]. The docking was accomplished with Lamarckian genetic algorithm [51]. Total ten bound conformations of each dye were created, and conformation with the best binding energy is used to visually understand the interaction between protein and dye molecules.

\section{Conclusions}

A laccase B gene from T. hirsuta MX2 was cloned and expressed in P. pastoris. A yeast recombinant with a yield of $2.59 \mathrm{U} / \mathrm{mL}$ of laccase was screened by methanol induction. The recombinant laccase was purified from culture medium and characterized. rLac1 showed the highest activity and $\mathrm{pH}$ stability under acidic condition. High concentration of $\mathrm{Cu}^{2+}$ $(100 \mathrm{mM})$ is able to increase the activity of rLac1. It also displayed a certain tolerance to organic solvents. Additionally, rLac1 showed excellent decolorization ability to RBBR, and its decolorization rates of synthetic dyes were improved compared with the native laccase (Lac1). The recombinant laccase rLac1 seems to be activity-induced by copper and have the ability to enhancement dye decolorization. The results suggestedrLac1 has potential application prospect in textile wastewater removal of dyes. 
Author Contributions: Conceptualization, Y.J. and C.P.; methodology, Y.J. and Q.H.; formal analysis, L.Z.; data curation, C.P.; writing—original draft preparation, Y.J.; writing—review and editing, C.P. and L.Z.; visualization, Y.J. and Q.H.; supervision, C.P.; funding acquisition, C.P. and L.Z. All authors have read and agreed to the published version of the manuscript.

Funding: This research was funded by National Natural Science Foundation of China (NSFC), grant number "32171802" and "31301923".

Institutional Review Board Statement: Not applicable.

Informed Consent Statement: Not applicable.

Data Availability Statement: The nucleotide sequence used to clone laccase gene is available from GenBank accession number MN327569. The crystal structure of laccase used for molecular docking is derived from PDB (ID: 1GYC).

Acknowledgments: We would like to thank Yongjian Xie and Guangzhi Xu at the Zhejiang A\&F University for their technical support.

Conflicts of Interest: The authors declare no conflict of interest.

\section{References}

1. Tkaczyk, A.; Mitrowska, K.; Posyniak, A. Synthetic organic dyes as contaminants of the aquatic environment and their implications for ecosystems: A review. Sci. Total. Environ. 2020, 717, 137222. [CrossRef] [PubMed]

2. Arora, S. Textile dyes: It's impact on environment and its treatment. J. Bioremed. Biodeg. 2014, 5, e146. [CrossRef]

3. Selvaraj, V.; Karthika, T.S.; Mansiya, C.; Alagar, M. An over review on recently developed techniques, mechanisms and intermediate involved in the advanced azo dye degradation for industrial applications. J. Mol. Struct. 2021, $1224,129195$. [CrossRef]

4. Abe, F.R.; Soares, A.M.V.M.; Oliveira, D.P.; Gravato, C. Toxicity of dyes to zebrafish at the biochemical level: Cellular energy allocation and neurotoxicity. Environ. Pollut. 2018, 235, 255-262. [CrossRef] [PubMed]

5. Garcia, V.S.G.; Tallarico, L.D.; Rosa, J.M.; Suzuki, C.F.; Roubicek, D.A.; Nakano, E.; Borrely, S.I. Multiple adverse effects of textile effluents and reactive Red 239 dye to aquatic organisms. Environ. Sci. Pollut. R. 2021, 28, 63202-63214. [CrossRef]

6. Robinson, T.; McMullan, G.; Marchant, R.; Nigam, P. Remediation of dyes in textile effluent: A critical review on current treatment technologies with a proposed alternative. Bioresource Technol. 2001, 77, 247-255. [CrossRef]

7. Singh, R.L.; Singh, P.K.; Singh, R.P. Enzymatic decolorization and degradation of azo dyes-A review. Int. Biodeter. Biodegr. 2015, 104, 21-31. [CrossRef]

8. Huang, Q.; Wang, C.; Zhu, L.; Zhang, D.; Pan, C. Purification, characterization, and gene cloning of two laccase isoenzymes (Lac1 and Lac2) from Trametes hirsuta MX2 and their potential in dye decolorization. Mol. Biol. Rep. 2020, 47, 477-488. [CrossRef]

9. Yadav, A.; Yadav, P.; Singh, A.K.; Kumar, V.; Sonawane, V.C.; Markandeya; Bharagava, R.N.; Raj, A. Decolourisation of textile dye by laccase: Process evaluation and assessment of its degradation bioproducts. Bioresour. Technol. 2021, 340, 125591. [CrossRef]

10. Morsi, R.; Bilal, M.; Iqbal, H.M.N.; Ashraf, S.S. Laccases and peroxidases: The smart, greener and futuristic biocatalytic tools to mitigate recalcitrant emerging pollutants. Sci. Total Environ. 2020, 714, 136572. [CrossRef]

11. Senthivelan, T.; Kanagaraj, J.; Panda, R.C. Recent trends in fungal laccase for various industrial applications: A eco-friendly approach-A review. Biotechnol. Bioproc. E. 2016, 21, 19-38. [CrossRef]

12. Legerska, B.; Chmelova, D.; Ondrejovic, M. Decolourization and detoxification of monoazo dyes by laccase from the white-rot fungus Trametes versicolor. J. Biotechnol. 2018, 285, 84-90. [CrossRef] [PubMed]

13. Yuan, H.; Chen, L.; Cao, Z.; Hong, F.F. Enhanced decolourization efficiency of textile dye Reactive Blue 19 in a horizontal rotating reactor using strips of BNC-immobilized laccase: Optimization of conditions and comparison of decolourization efficiency. Biochem. Eng. J. 2020, 156, 107501. [CrossRef]

14. Sun, Y.; Liu, Z.L.; Hu, B.Y.; Chen, Q.J.; Yang, A.Z.; Wang, Q.Y.; Li, X.F.; Zhang, J.Y.; Zhang, G.Q.; Zhao, Y.C. Purification and characterization of a thermo- and $\mathrm{pH}$-stable laccase from the litter-decomposing fungus Gymnopusluxurians and laccase mediator systems for dye decolorization. Front. Microbiol. 2021, 12, 672620. [CrossRef]

15. Mate, D.M.; Alcalde, M. Laccase: A multi-purpose biocatalyst at the forefront of biotechnology. Microb. Biotechnol. 2017, 10, 1457-1467. [CrossRef]

16. Zapata-Castillo, P.; Villalonga-Santana, L.; Islas-Flores, I.; Rivera-Muñoz, G.; Ancona-Escalante, W.; Solís-Pereira, S. Synergistic action of laccases from Trametes hirsuta Bm2 improves decolourization of indigo carmine. Lett. Appl. Microbiol. 2015, 61, 252-258. [CrossRef] [PubMed]

17. Savinova, O.S.; Moiseenko, K.V.; Vavilova, E.A.; Tyazhelova, T.V.; Vasina, D.V. Properties of two laccases from the Trametes hirsuta 072 multigene family: Twins with different faces. Biochimie 2017, 142, 183-190. [CrossRef]

18. Couto, S.R. Decolouration of industrial azo dyes by crude laccase from Trametes hirsuta. J. Hazard. Mater. 2007, 148, 768-770. [CrossRef] 
19. Ancona-Escalante, W.; Tapia-Tussell, R.; Pool-Yam, L.; Can-Cauich, A.; Lizama-Uc, G.; Solis-Pereira, S. Laccase-mediator system produced by Trametes hirsuta Bm-2 on lignocellulosic substrate improves dye decolorization. 3 Biotech 2018, 8, 298. [CrossRef]

20. Anita, S.H.; Ardiati, F.C.; Oktaviani, M.; Sari, F.P.; Nurhayat, O.D.; Ramadhan, K.P.; Yanto, D.H.Y. Immobilization of laccase from Trametes hirsuta EDN 082 in light expanded clay aggregate for decolorization of Remazol Brilliant Blue R dye. Bioresour. Technol. Rep. 2020, 12, 100602. [CrossRef]

21. Yanto, D.H.Y.; Guntoro, M.A.; Nurhayat, O.D.; Anita, S.H.; Oktaviani, M.; Ramadhan, K.P.; Pradipta, M.F.; Watanabe, T. Biodegradation and biodetoxification of batik dye wastewater by laccase from Trametes hirsuta EDN 082 immobilised on light expanded clay aggregate. 3 Biotech 2021, 11, 247. [CrossRef] [PubMed]

22. Moiseenko, K.V.; Vasina, D.V.; Farukshina, K.T.; Savinova, O.S.; Glazunova, O.A.; Fedorova, T.V.; Tyazhelova, T.V. Orchestration of the expression of the laccase multigene family in white-rot basidiomycete Trametes hirsuta 072: Evidences of transcription level subfunctionalization. Fungal Biol. 2018, 122, 353-362. [CrossRef] [PubMed]

23. Savinova, O.S.; Moiseenko, K.V.; Vavilova, E.A.; Chulkin, A.M.; Fedorova, T.V.; Tyazhelova, T.V.; Vasina, D.V. Evolutionary relationships between the laccase genes of Polyporales: Orthology-based classification of laccase isozymes and functional insight from Trametes hirsuta. Front. Microbiol. 2019, 10, 152. [CrossRef]

24. Vasina, D.V.; Pavlov, A.R.; Koroleva, O.V. Extracellular proteins of Trametes hirsuta st. 072 induced by copper ions and a lignocellulose substrate. BMC Microbiol. 2016, 16, 106. [CrossRef] [PubMed]

25. Yang, J.; Li, W.; Ng, T.B.; Deng, X.; Lin, J.; Ye, X. Laccases: Production, expression regulation and applications in pharmaceutical biodegradation. Front. Microbiol. 2017, 8, 00832. [CrossRef] [PubMed]

26. Savinova, O.S.; Zorov, I.N.; Vasina, D.V.; Sinitsyn, A.P.; Fedorova, T.V. The minor recombinant laccase isozymes of Trametes hirsuta 072: Preparation and properties. Mosc. Univ. Chem. Bull. 2019, 74, 173-179. [CrossRef]

27. Yaver, D.S.; Xu, F.; Golightly, E.J.; Brown, K.M.; Brown, S.H.; Rey, M.W.; Schneider, P.; Halkier, T.; Mondorf, K. Purification, characterization, molecular cloning, and expression of two laccase genes from the white rot basidiomycete Trametesvillosa. Appl. Environ. Microb. 1996, 62, 834-841. [CrossRef]

28. Moiseenko, K.V.; Savinova, O.S.; Vasina, D.V.; Kononikhin, A.S.; Tyazhelova, T.V.; Fedorova, T.V. Laccase isoenzymes of Trametes hirsuta LE-BIN072: Degradation of industrial dyes and secretion under the different induction conditions. Appl. Biochem. Microbiol. 2018, 54, 834-841. [CrossRef]

29. Bronikowski, A.; Hagedoorn, P.-L.; Koschorreck, K.; Urlacher, V.B. Expression of a new laccase from Moniliophthoraroreri at high levels in Pichia pastoris and its potential application in micropollutant degradation. AMB Express 2017, 7, 73. [CrossRef]

30. Garg, N.; Bieler, N.; Kenzom, T.; Chhabra, M.; Ansorge-Schumacher, M.; Mishra, S. Cloning, sequence analysis, expression of Cyathusbulleri laccase in Pichia pastoris and characterization of recombinant laccase. BMC Biotechnol. 2012, 12, 75. [CrossRef]

31. Xu, G.; Wang, J.; Yin, Q.; Fang, W.; Xiao, Y.; Fang, Z. Expression of a thermo- and alkali-philic fungal laccase in Pichia pastoris and its application. Protein Express. Purif. 2019, 154, 16-24. [CrossRef] [PubMed]

32. Antosova, Z.; Sychrova, H. Yeast hosts for the production of recombinant laccases: A review. Mol. Biotechnol. 2016, 58, 93-116. [CrossRef] [PubMed]

33. Yin, Q.; Zhou, G.; Peng, C.; Zhang, Y.; Kues, U.; Liu, J.; Xiao, Y.; Fang, Z. The first fungal laccases with an alkaline pH optimum obtained by directed evolution and its application in indigo dye decolorization. AMB Express 2019, 9, 151. [CrossRef] [PubMed]

34. Huy, N.D.; Le, N.T.M.; Chew, K.W.; Park, S.-M.; Show, P.L. Characterization of a recombinant laccase from Fusarium oxysporum HUIB02 for biochemical application on dyes removal. Biochem. Eng. J. 2021, 168, 107958. [CrossRef]

35. Xu, G.; Wu, Y.; Zhang, Y.; Fang, W.; Xiao, Y.; Fang, Z. Role of N-glycosylation on the specific activity of a Coprinopsiscinerea laccase Lcc9 expressed in Pichia pastoris. J. Biosci. Bioeng. 2019, 128, 518-524. [CrossRef]

36. Savinova, O.S.; Chulkin, A.M.; Savinova, T.S.; Vavilova, E.A.; Vasina, D.V.; Solyev, P.N.; Fedorova, T.V. Construction of the heterologous laccase producer Aspergillus nidulans lac№4 $\left(\arg B^{-}\right)$and its application for the progesterone transformation. Appl. Biochem. Microbiol. 2020, 56, 321-328. [CrossRef]

37. Koschorreck, K.; Richter, S.M.; Swierczek, A.; Beifuss, U.; Schmid, R.D.; Urlacher, V.B. Comparative characterization of four laccases from Trametes versicolor concerning phenolic C-C coupling and oxidation of PAHs. Arch. Biochem. Biophys. 2008, 474, 213-219. [CrossRef]

38. Yang, X.; Wu, Y.; Zhang, Y.; Yang, E.; Qu, Y.; Xu, H.; Chen, Y.; Irbis, C.; Yan, J. A thermo-active laccase isoenzyme from Trametestrogii and its potential for dye decolorization at high temperature. Front. Microbiol. 2020, 11, 241. [CrossRef]

39. Navada, K.K.; Kulal, A. Kinetic characterization of purified laccase from Trametes hirsuta: A study on laccase catalyzed biotransformation of 1,4-dioxane. Biotechnol. Lett. 2021, 43, 613-626. [CrossRef]

40. Vasina, D.V.; Mustafaev, O.N.; Moiseenko, K.V.; Sadovskaya, N.S.; Glazunova, O.A.; Tyurin, A.A.; Fedorova, T.V.; Pavlov, A.R.; Tyazhelova, T.V.; Goldenkova-Pavlova, I.V.; et al. The Trametes hirsuta 072 laccase multigene family: Genes identification and transcriptional analysis under copper ions induction. Biochimie 2015, 116, 154-164. [CrossRef]

41. Si, J.; Peng, F.; Cui, B. Purification, biochemical characterization and dye decolorization capacity of an alkali-resistant and metal-tolerant laccase from Trametespubescens. Bioresour. Technol. 2013, 128, 49-57. [CrossRef] [PubMed]

42. Liu, C.; Zhang, W.; Qu, M.; Pan, K.; Zhao, X. Heterologous expression of laccase from Lentinula edodes in Pichia pastoris and its application in degrading rape straw. Front. Microbiol. 2020, 11, 1086. [CrossRef] [PubMed] 
43. Guo, X.; Zhou, S.; Wang, Y.; Song, J.; Wang, H.; Kong, D.; Zhu, J.; Dong, W.; He, M.; Hu, G.; et al. Characterization of a highly thermostable and organic solvent-tolerant copper-containing polyphenol oxidase with dye-decolorizing ability from Kurthiahuakuii LAM0618 ${ }^{\mathrm{T}}$. PloS ONE 2016, 11, 164810. [CrossRef]

44. Keum, Y.S.; Li, Q.X. Fungal laccase-catalyzed degradation of hydroxy polychlorinated biphenyls. Chemosphere 2004, 56, 23-30. [CrossRef]

45. Morozova, O.V.; Shumakovich, G.P.; Shleev, S.V.; Yaropolov, Y.I. Laccase-mediator systems and their applications: A review. Appl. Biochem. Microbiol. 2007, 43, 523-535. [CrossRef]

46. Maestre-Reyna, M.; Liu, W.C.; Jeng, W.Y.; Lee, C.C.; Hsu, C.A.; Wen, T.N.; Wang, A.H.J.; Shyur, L.F. Structural and functional roles of glycosylation in fungal laccase from Lentinus sp. PloS ONE 2015, 10, 120601. [CrossRef]

47. Zhang, Y.; Hu, P.; Muhammad, Y.; Tang, Y.; Shao, S.; Gao, Z.; Wang, J.; Wang, R.; Hu, Y.; Kuang, L.; et al. High-density immobilization of laccase on hollow nano-sphere $\mathrm{NH}_{2}$-MIL88 (Fe) host with interfacial defects to improve enzyme activity and stability for remazol brilliant blue R decolorization. Chem. Eng. J. 2021, 405, 127003. [CrossRef]

48. Cannatelli, M.D.; Ragauskas, A.J. Two decades of laccases: Advancing sustainability in the chemical industry. Chem. Rec. 2017, 17, 122-140. [CrossRef]

49. Morris, G.M.; Huey, R.; Lindstrom, W.; Sanner, M.F.; Belew, R.K.; Goodsell, D.S.; Olson, A.J. AutoDock4 and AutoDockTools4: Automated docking with selective receptor flexibility. J. Comput. Chem. 2009, 30, 2785-2791. [CrossRef]

50. Seeliger, D.; Groot, B.L. Ligand docking and binding site analysis with PyMOL and Autodock/Vina. J. Comput.-Aided Mol. Des. 2010, 24, 417-422. [CrossRef]

51. Morris, G.M.; Goodsell, D.S.; Halliday, R.S.; Huey, R.; Hart, W.E.; Belew, R.K.; Olson, A.J. Automated docking using a Lamarckian genetic algorithm and an empirical binding free energy function. J. Comput. Chem. 1998, 19, 1639-1662. [CrossRef] 